\title{
Thermodynamic Assessment of Binary Erythritol-Xylitol Phase Diagram for Phase Change Materials Design
} \section{Saman Nimali Gunasekara ${ }^{1}$, Huahai Mao², Sedigheh Bigdeli², Justin NingWei Chiu ${ }^{1}$, and Viktoria Martin $^{1}$}

(saman.gunasekara@energy.kth.se, huahai@kth.se, sedigheh@kth.se, justin.chiu@energy.kth.se, viktori a.martin@energy.kth.se)

${ }^{1}$ Department of Energy Technology, KTH Royal Institute of Technology, Brinellvägen 68, 10044 Stockholm, Sweden. ${ }^{2}$ Department of Materials Science and Engineering, KTH Royal Institute of Technology, Brinellvägen 23, 10044 Stockholm, Sweden

${ }^{*}$ Corresponding author (Office: +46 8 7907476, Mobile: +46 736523339)

\section{Abstract}

Here, the experimental phase equilibrium data of the erythritol-xylitol system were thermodynamically optimized, to explore compositions suitable as phase change materials (PCMs) for thermal energy storage (TES). A previous experimental study revealed that erythritol-xylitol was a partially isomorphous system with a eutectic. In the thermodynamic evaluation, the CALPHAD method was employed coupling the phase diagram and thermodynamic property information. There, both unary and binary systems' experimental data were taken into account, and all phases were described using the substitutional solution model. Finally, a self-consistent thermodynamic description for the erythritol-xylitol system was achieved. The calculated eutectic point is at $76.7^{\circ} \mathrm{C}$ and 26.8 mol\% erythritol, agreeing well with the experimental data. The calculated phase diagram better-verifies the systems' solidus and the solvus, disclosing the stable phase relations. Based on the Gibbs energy minimization, phase diagrams can be predicted for the binary and higher order systems, provided the component subsystems are thermodynamically assessed beforehand. In conclusion, to move forward beyond e.g. non-isomorphous simple eutectic systems, methods using Gibbs free energy minimization from a fundamental point-of-view such as CALPHAD are essential.

Keywords: thermal energy storage (TES); phase change material (PCM); erythritol-xylitol phase diagram; Gibbs free energy minimization; thermodynamic optimization; CALPHAD

\section{Nomenclature}

$\begin{array}{ll}\text { Abbreviations } & \\ \text { AMPL } & \text { 2-amino-2-methyl-1,3-propanediol } \\ \text { BCC } & \text { Body-Centered Cubic } \\ \text { CALPHAD } & \text { CALculation of PHAse Diagrams } \\ \text { DSC } & \text { Differential Scanning Calorimetry } \\ \text { E } & \text { Eutectic } \\ \text { Et } & \text { Erythritol } \\ \text { FCC } & \text { Face-Centered Cubic } \\ \text { FESEM } & \text { Field-Emission Scanning Electron Microscopy }\end{array}$




$\begin{array}{ll}\text { IRT } & \text { Infra-Red Thermography } \\ \text { NPG } & \text { Neopentylglycol } \\ \text { PCMs } & \text { Phase Change Materials } \\ \text { PE } & \text { Phase Equilibrium } \\ \text { PER } & \text { Pentaerythritol } \\ \text { PG } & \text { Pentaglycerine } \\ \text { PLM } & \text { Polarized Light Thermo-Microscopy } \\ \text { SLE } & \text { Solid-Liquid Equilibrium } \\ \text { TES } & \text { Thermal Energy Storage } \\ \text { T-History } & \text { Temperature-History } \\ \text { TRIS } & \text { Tris(hydroxymethyl)aminomethane } \\ \text { UNIFAC } & \text { Universal Quasi Chemical Functional Group Activity Coefficients } \\ \text { XRD } & \text { X-ray Diffraction } \\ \text { XY } & \text { Xylitol }\end{array}$

\section{Symbols, subscripts}

$\begin{array}{ll}\text { config } & \text { Configurational } \\ c_{p} & \text { Specific heat at constant pressure }(\mathrm{J} /(\mathrm{mol} / \mathrm{K})) \\ h, H m & \text { Enthalpy }(\mathrm{J} / \mathrm{mol}) \\ { }_{G} & \text { Molar Gibbs free energy }(\mathrm{J} / \mathrm{mol}) \\ { }^{E} G_{m} & \text { Excess molar Gibbs free energy }(\mathrm{J} / \mathrm{mol}) \\ \gamma & \text { Activity coefficient } \\ i, k, j & \text { Any component } \\ \mathrm{L} & \text { Liquid } \\ { }^{0} L,{ }^{1} L & \text { Interaction parameters for excess Gibbs energy } \\ \mathrm{m} & \text { Melting/Molar } \\ \mathrm{phys} & \text { Physical } \\ R & \text { Gas constant }(\mathrm{J} / \mathrm{mol} / \mathrm{K}) \\ \mathrm{S} & \text { Solid } \\ \mathrm{srf} & \text { Surface } \\ T & \text { Temperature }(\mathrm{K}) \\ \mathrm{tr} & \text { Transition } \\ \mathrm{X} & \text { Mole fraction }\end{array}$

\section{Introduction}

Improved efficiencies and better management in the energy systems can be realized by integrating thermal energy storage (TES) using phase change materials (PCMs). PCMs can replace fossil-based heating and cooling, by e.g. harvesting excess thermal energy from industries, power plants and like ( [1], [2]), for use at different locations and time (e.g. in district heating [3]). TES with PCMs thereby decrease the fossil fuel-based $\mathrm{CO}_{2}$ emissions [4], while is also attractive for peak shaving and load shifting [5]-[7]. Material challenges keeping PCMs from reaching commercialization to a large extent include cost, phase separation 
and supercooling. Bulk blends could serve as cost-effective PCMs, if their phase equilibrium is well established and understood. Thereby, blend compositions that do not phase separate and still have pure material-like sharp phase change (i.e., congruent melting, or, eutectics if supercooling is absent), can be accurately chosen as PCMs [8]-[10].

Polyols are a renewable material category generally safe for handling, with melting temperatures and enthalpies attractive for cooling and low-temperature heating [11]. They are emerging as PCMs, with various pure polyols (e.g. [11]-[18]) as well as blends ( [19]- [25]) being evaluated as PCMs. These include the binary polyols system erythritol-xylitol, proposed with a non-isomorphous simple eutectic phase diagram ( [19], [20]), or with a phase diagram containing a eutectic with solid-solid phase changes implying a partially isomorphous system ( [21], [25]). The non-isomorphous simple eutectic deduction was based on experimental assessments using: Differential Scanning Calorimetry (DSC) [19], [20]; Polarized Light thermo-Microscopy (PLM) [19]; X-ray Diffraction (XRD) [19]; Infra-Red thermography (IRT) [20], and theoretical modelling specific to non-isomorphous simple eutectic systems [19], [20]. The partially isomorphous system was deduced based on experimental evaluations with the Temperature-History (THistory) method [21], [25], complemented with Tammann Plots, XRD and Field-Emission Scanning Electron Microscopy (FESEM) [25].

To complement the experimental evaluations that yielded a partially isomorphous behavior, the erythritolxylitol binary phase diagram is theoretically evaluated herein. For that, the CALPHAD (CALculation of PHAse Diagrams) method [26] based on Gibbs free energy minimization is employed, using the PARROT module in the iterative optimization software Thermo-Calc [27]. The CALPHAD method is considered a suitable choice to evaluate the erythritol-xylitol phase diagram, as this method can evaluate any phase equilibrium type and any material type. This is in-contrast to the previous theoretical approaches employed on the system, which were restricted to a non-isomorphous simple eutectic. With the thermodynamic assessment, it is expected herein to further confirm the erythritol-xylitol system's phase equilibrium behavior forming a partially isomorphous eutectic.

\subsection{Background}

The previous theoretical assessments of the erythritol-xylitol phase diagram were conducted using solidliquid equilibrium (SLE) expressions expressed with respect to the activity coefficients of the components [19], [20]. There, the correction terms for the solid-solid transitions of the components and for the specific heat $\left(c_{p}\right)$ difference between the liquid and solid were neglected, as these are small compared to the activity coefficients' uncertainties [19], [20]. Based on the experimental results indicating a nonisomorphous simple eutectic behavior (thus considering that the solid components are immiscible), the solid-state activity coefficients were assumed to be equal to unity [19], [20]. Then, to determine the SLE, in one approach, the liquid-state activity coefficients were determined by employing the modified UNIFAC (Universal quasichemical functional group activity coefficients) method [19]. In another approach, ideal liquid solutions were assumed, and hence assuming the liquid-state activity coefficients also as equal to unity [19], [20]. Overall, these theoretical assessments conducted on the erythritol-xylitol phase diagram so far are restricted to non-isomorphous simple eutectic systems. Hence, such specific theoretical methods cannot be used to thermodynamically evaluate the partially isomorphous eutectic behavior identified on the erythritol-xylitol system [21], [25]. Therefore, for the thermodynamic assessment of the 
erythritol-xylitol system based on this new understanding of its phase equilibrium, the CALPHAD method was chosen as a suitable approach, as it can evaluate any material type and any phase change behavior.

With the CALPHAD method, the Gibbs free energy of a system is minimized to find its equilibrium phases. By employing the CALPHAD method, numerous organic and inorganic multicomponent phase diagrams with complex phase change characteristics have been optimized thermodynamically (e.g. [10], [28]- [44]). For that, various optimizer tools have been used, such as: LIQFIT combined with Prophase on binary systems (e.g. [28]- [33]); TXY-CALC on ternary systems (e.g. [29]-[31]); FactSage (OptiSage module) on binary-quaternary systems (e.g. [42]) or, Thermo-Calc on numerous multicomponent systems (e.g. [10], [34]-[41], [43]). In these CALPHAD-based assessments, a part of the total molar Gibbs free energy $\left(G_{m}\right)$ of the system was expressed in-terms of the excess molar Gibbs free energy $\left({ }^{E} G_{m}\right)$. There, the excess molar Gibbs free energy was often expressed in the form of a Redlich-Kister polynomial for binary ( [10], [29][31], [34]- [41], [43], [44]), ternary ( [10], [37], [38]) and quaternary ( [42]) systems. In certain ternary systems evaluations, the excess molar Gibbs free energy was expressed according to the Kohler's method ${ }^{1}$ (e.g. [29]-[32]).

By employing the CALPHAD method together with Thermo-Calc (PARROT module), the phase diagrams of: the binary polyol systems 2-amino-2-methyl-1,3-propanediol (AMPL)-neopentylglycol (NPG) [34], [36], pentaerythritol (PER)-AMPL [35], [36], and AMPL-pentaglycerine (PG) [43]; the binary amine-polyol systems tris(hydroxymethyl)aminomethane (TRIS)-NPG [36], TRIS-AMPL [39], and TRIS-PG [43]; and the ternary polyol systems PER-PG-NPG [10], [37] and PER-NPG-AMPL [38]; have been thermodynamically assessed. These phase diagrams contain complex phase equilibrium features including eutectics, peritectics, eutectoids and peritectoids. The phase diagrams of the AMPL-NPG [34], [36], PER-AMPL [35], [36], and AMPL-TRIS [39], TRIS-PG, AMPL-PG [43], PER-PG-NPG [10], and PER-NPG-AMPL [38] systems were thermodynamically optimized, obtaining satisfactory agreements with the experimental data. For the TRIS-NPG system, an unoptimized phase diagram using ideal solutions assumption was found to have reasonable agreements with the experimental data, possibly owing to small excess molar Gibbs free energy parameters of the system [36]. In these organic systems, different liquid and solid solution phases were thermodynamically described by employing: regular and sub-regular solution models [10], [34], [35], [37], [38], [43]; substitutional solution models [10], [37], [38]; and ideal solution models [34].

Evidently, the CALPHAD method is an attractive choice for modelling a materials system's deviations from the ideal behavior, unlike e.g. the specific methods employed on the erythritol-xylitol assessment in literature, which were restricted to ideal or dilute solutions. Besides the flexibility in evaluating complex phase equilibrium systems, another attractive attribute of CALPHAD is the ability to predict higher-order system's phase diagrams, when the corresponding sub-systems are thermodynamically assessed already. For instance, the PER-PG-NPG ternary phase diagram was first theoretically predicted using the binary phase equilibrium descriptions of the involved components [37]. Thereafter, the ternary phase diagram predictions were refined by employing inputs from experimental and further thermodynamic assessments [10]. Therefore, the CALPHAD method is instrumental in predicting the phase equilibrium of multicomponent systems, in designing PCMs out of bulk blends.

\footnotetext{
${ }^{1}$ Refer Saunders and Miodownik [26] for details.
} 
Overall, the CALPHAD method is undoubtedly ideal for evaluating complex phase diagrams of organic and inorganic systems, in the focus of designing PCMs from blends. Specifically, many binary and ternary organic phase diagrams, with a majority being of polyols, have been successfully thermodynamically optimized using the CALPHAD method combined with Thermo-Calc PARROT module. Therefore, the CALPHAD method with Thermo-Calc (PARROT module) is chosen as an appropriate approach to thermodynamically evaluate the erythritol-xylitol binary polyols phase diagram, containing a eutectic in a partially isomorphous system [25]. This is in-contrast to the specific theoretical methods employed so far in literature to study the system, which were restricted to non-isomorphous simple eutectic behavior.

\subsection{Aims}

The aims of the present study are to: employ a CALPHAD-type thermodynamic assessment taking into account both thermodynamic properties such as enthalpy and heat capacity measurements as well as experimental phase diagram information, to establish a self-consistent thermodynamic dataset; and using this dataset to predict the equilibrium phase diagram, irrespective of the chemical characteristics of the components. In short, the CALPHAD approach applying the Gibbs free energy minimization was chosen to evaluate the erythritol-xylitol system. As the optimization tool, Thermo-Calc (PARROT module) was chosen.

\section{Thermodynamic Assessment of the Erythritol-Xylitol Phase Diagram with the CALPHAD Method using Thermo-Calc}

For the thermodynamic phase equilibrium evaluation of the erythritol-xylitol binary polyols system, the CALPHAD method was employed, as detailed herein. There, the thermodynamic models employed are described in section 2.1, while the experimental information on the system used are concisely presented in section 2.2. The thermodynamic optimization was conducted as explained in section 2.3.

In theory, a binary system is essentially made of two elements. However, in common lay-terms, often a binary phase diagram is also made of two components, which essentially is a multicomponent system made of the number of elements the components have. Hence, the erythritol-xylitol system is in fact a ternary system of the three elements $\mathrm{C}, \mathrm{H}$ and $\mathrm{O}$. Considering the chemical stability of erythritol and xylitol in their individual and mixing states, neither chemical decompositions nor new sub-components formation occur beyond the erythritol-xylitol combination. This was verified in the experimental evaluations [25]. Thus, the erythritol-xylitol system is here thermodynamically treated as a pseudo-binary system. For the engineering purpose of designing PCM blends using phase diagrams, the erythritol-xylitol system will nevertheless be referred to as a binary system.

The erythritol-xylitol system was experimentally found [25] to contain the liquid phase, and the solidsolutions of erythritol and xylitol (denoted as $S_{\mathrm{Et}}$ and $\mathrm{S}_{\mathrm{xy}}$ here) with mutual solubility ${ }^{2}$. The stable state of erythritol is tetragonal [45], and the stable state of xylitol is orthorhombic [46]. For the sake of simplification in notation here these are approximated and denoted to be, BCC (body-centered cubic) and FCC (face-centered cubic) structures, respectively. Thus, their solid solutions $\mathrm{S}_{\mathrm{Et}}$ and $\mathrm{S}_{\mathrm{Xy}}$ are also modeled as BCC and FCC respectively, because, a solid solution retains the crystal structure of the solvent

\footnotetext{
2 i.e., $\mathrm{S}_{\mathrm{Et}}$ is a solid solution where erythritol is the solvent and xylitol is the solute, while for $\mathrm{S}_{\mathrm{xy}}$ vice-versa applies.
} 
component [47]. The phase equilibrium of the three phases in the erythritol-xylitol system: liquid, BCC and FCC, can be described based on the Gibbs energy minimization of the whole system [26].

\subsection{Thermodynamic Models}

Using the substitutional solution models [26], [44], the molar Gibbs free energy of the solution phases liquid, BCC and FCC, in the erythritol-xylitol system are described using Eqn. 1-Eqn. 4. There, Xy represents the unary xylitol, while, the unary erythritol was referred to as Et because of an already existing component Erbium denoted as Er in the CALPHAD database.

$$
\begin{array}{cc}
G_{m}={ }^{\text {srf }} G_{m}+{ }^{\text {config }} G_{m}+{ }^{E} G_{m}+{ }^{\text {phys }} G_{m} & \text { Eqn. 1 } \\
{ }^{\text {srf }} G_{m}=x_{E t}{ }^{\circ} G_{E t}+x_{X y}{ }^{\circ} G_{X y} & \text { Eqn. 2 } \\
{ }^{\text {config }} G_{m}=R T\left(x_{E t} \ln x_{E t}+x_{X y} \ln x_{X y}\right) & \text { Eqn. 3 } \\
{ }^{E} G_{m}=X_{E t} X_{X y} \sum_{v}^{n} L_{E t, X y}^{v}\left(x_{E t}-x_{X y}\right) v & \text { Eqn. 4 }
\end{array}
$$

In Eqn. 2, the molar Gibbs energy of erythritol and xylitol are respectively denoted with ${ }^{\circ} G_{E t}$ and ${ }^{\circ} G_{X y}$. In Eqn. 1 and Eqn. 2, ${ }^{\text {srf }} G$ is the average energy regarding the surface of reference, and ${ }^{c o n f i g} G$ represents the contributions of the configurational entropy to the Gibbs energy due to chemical mixing. The system' deviations from an ideal solution are described by the excess Gibbs energy ${ }^{E} G_{m}$, which can be expressed in terms of a Redlich-Kister polynomial as shown in Eqn. 4. There, the interaction parameters $L_{E t, X y}^{v}$ where $v=0,1,2, \ldots$ can be expressed as linear functions of temperature. They are adjustable parameters to be optimized according to the experimental information. In the present case just ${ }^{0} L$ and ${ }^{1} L$ were found sufficient to fit the experimental phase diagram. In Eqn. 1, ${ }^{\text {phys }} G$ expresses the physical contributions to the Gibbs energy, such as magnetic transitions, which were assumed negligible for the erythritol-xylitol system.

\subsection{Experimental Pure Components and Phase Diagram Data}

As was explained (section 1), the erythritol-xylitol binary phase diagram has been so far presented in open literature by only a few studies ( [19]- [21], [25]). There, it was proposed to be a non-isomorphous simple eutectic system [19], [20] or, to be a partially isomorphous system containing a eutectic [21], [25]. Regardless of the disparities on the overall phase diagram of the system, the eutectic point is confirmed. However, it has disparities on the composition and temperature proposed: to be 25 [19], 25-30 [25], or 36 [20] mol\% erythritol, at $82^{\circ} \mathrm{C}$ [19], [20] or $77^{\circ} \mathrm{C}$ [25], respectively. Gunasekara et al. [25] observed partial miscibility of the system over more than three melting cycles in the Temperature-History (T-history) cycling, later confirmed via evaluations in high-temperature X-Ray diffraction (XRD) and Field-emission Scanning Electron Microscopy (FESEM). Although the other evaluations also used multiple assessment methods (Differential Scanning Calorimetry (DSC) [19], [20], Infrared Thermography (IRT) [20], Polarized Light (thermo-) Microscopy (PLM) and X-Ray Diffraction (XRD) [19] combined with thermodynamic modelling [19], [20], c.f. section 1.1), the number of cycles the system was evaluated were not specified. Hence, in this present work, the partially isomorphous eutectic deduction [25] is chosen for the thermodynamic evaluation of the blend. 
Gunasekara et al. [25] also have determined the pure component's temperatures and enthalpies of fusion, and the specific heat capacities. However, the signal to noise ratio encountered with the T-History method was rather small, which caused a larger uncertainty in the calculated $c_{p}$ and enthalpy. Therefore, the pure component properties from Tong et al. for erythritol [48] and xylitol [49] were used in this thermodynamic assessment. There, the $c_{p}$ measurements were performed using an automated adiabatic calorimeter under extremely slow heating rates [48], [49], which produced smoother $c_{p}$ profiles, and enthalpies with higher accuracy. The enthalpy of fusion of erythritol and xylitol are also used as proposed by Tong et al., as equal to: $37920 \mathrm{~J} / \mathrm{mol}$ and $33260 \mathrm{~J} / \mathrm{mol}$ [48], [49] (i.e., $311 \mathrm{~J} / \mathrm{g}$ and $219 \mathrm{~J} / \mathrm{g}$ ), while their melting temperatures were chosen as to be at $393.85 \mathrm{~K}$ and $368.32 \mathrm{~K}$ (i.e., $120.7^{\circ} \mathrm{C}$ and $94.8^{\circ} \mathrm{C}$ ) respectively [25]. Combining these pure component properties from Tong et al. [48], [49] with the phase diagram of Gunasekara et al. [25], the thermodynamic assessment was performed. In the experimental study, the highest eutectic enthalpy was obtained on the 25 mol\% erythritol, and the minimum melting point in the liquidus was observed at 30 mol\% erythritol, respectively from the evaluated compositions [25]. Therefore, in this work, the experimental eutectic composition is chosen to be $\sim 27 \mathrm{~mol} \%$ erythritol.

\subsection{Thermodynamic Optimization}

The thermodynamic assessment of the erythritol-xylitol system was done by optimizing the thermodynamic parameters by using the iterative software Thermo-Calc [27], using its PARROT module. Considering the polyols erythritol (BCC) and xylitol (FCC) as the two pure constituents of the system, the BCC and FCC phases were first optimized using the thermal properties from Tong et al. [48], [49]. Thereafter their respective liquid phase was optimized to reproduce the experimental melting temperature and enthalpy of fusion of each unary. Finally, the binary experimental data from Gunasekara et al. [25] were fitted via thermodynamic optimization of the interaction parameters in the liquid and in the two solid solutions $\left(\mathrm{S}_{\mathrm{Et}}\right.$ and $\left.\mathrm{S}_{\mathrm{Xy}}\right)$ as well.

\section{Results and Discussion}

The results of the optimized parameters of the Gibbs free energy expressions for the pure erythritol, pure xylitol, and the description of the erythritol-xylitol binary system for the BCC (i.e., $\mathrm{S}_{\mathrm{Et}}$ ), FCC (i.e., $\mathrm{S}_{\mathrm{Xy}}$ ) and liquid solution phases are summarized in Table 1.

Table 1. The Gibbs free energy expression parameters for the unary and binary systems (with the stable solid phase of Erythritol or its solid solution $S_{E t}$ denoted with BCC, and the stable solid phase of Xylitol or its solid solution $S_{X y}$ denoted with FCC)

\begin{tabular}{|c|c|c|}
\hline \multicolumn{3}{|c|}{ Unary systems } \\
\hline Component & Phase & Molar Gibbs free energy expression parameters \\
\hline \multirow[t]{4}{*}{ Erythritol } & \multirow[t]{2}{*}{ BCC } & $G_{B C C E T_{298.15-393.85 K}}=-23279.19-6062.77 T-5.56 T \ln T-0.24 T^{2}$ \\
\hline & & $G B C C E T_{393.85-6000 K}=-115815.33-4031.58 T-322.40 T \ln T+1.25 \cdot 10^{26} T^{-9}$ \\
\hline & \multirow[t]{2}{*}{ LIQUID } & GLIQET $_{298.15-393.85 K}=G B C C E T+30858.74-75.37 T-7.99 \cdot 10^{-16} T^{7}$ \\
\hline & & $G L I Q E T_{393.85-6000 K}=-72409.69-4140.39 T-322.40 T \ln T$ \\
\hline \multirow[t]{3}{*}{ Xylitol } & \multirow[t]{2}{*}{ FCC } & $G F C C X Y_{298.15-368.32 K}=-33566.85-6060.23 T-3.39 T \ln T-0.37 T^{2}$ \\
\hline & & $G F C C X Y_{368.32-6000 K}=-144331.06-3422.14 T-422.00 T \ln T+7.64 \cdot 10^{25} T^{-9}$ \\
\hline & LIQUID & $G L I Q X Y_{298.15-368.32 K}=G F C C X Y+25401.72-65.41 T-1.42 \cdot 10^{-15} T^{7}$ \\
\hline
\end{tabular}




\begin{tabular}{|c|c|}
\hline & $G L I Q X Y_{368.32-6000 K}=-104945.94-3527.40 T-422.00 T \ln T$ \\
\hline \multicolumn{2}{|c|}{ Binary system } \\
\hline \multirow[t]{4}{*}{ LIQUID } & ${ }^{\circ} G_{E t}^{L I Q U I D}-H_{E t}^{S E R}=G L I Q E T$ \\
\hline & ${ }^{\circ} G_{X y}^{L I Q U I D}-H_{X y}^{S E R}=G L I Q X Y$ \\
\hline & ${ }^{0} L_{E t, X y}^{L I Q U I D}=70489.20-209.06 T$ \\
\hline & ${ }^{1} L_{E t, X y}^{L I Q U I D}=6387.69$ \\
\hline \multirow[t]{3}{*}{ BCC } & ${ }^{\circ} G_{E t}^{B C C}-H_{E t}^{S E R}=G B C C E T$ \\
\hline & ${ }^{\circ} G_{X y}^{B C C}-H_{X y}^{S E R}=G B C C X Y=G F C C X Y+1326.77$ \\
\hline & ${ }^{0} L_{E t, X y}^{B C C}=14848.62-34.66 T$ \\
\hline \multirow[t]{3}{*}{ FCC } & ${ }^{\circ} G_{E t}^{F C C}-H_{E t}^{S E R}=G F C C E T=G B C C E T+461.04$ \\
\hline & ${ }^{\circ} G_{X y}^{F C C}-H_{X y}^{S E R}=G F C C X Y$ \\
\hline & ${ }^{0} L_{E t, X y}^{F C C}=50424.00-128.73 T$ \\
\hline
\end{tabular}

The calculated specific heat and enthalpies of the unary components from the present assessments are shown: for pure erythritol in Figure 1 and Figure 2; and for pure xylitol in Figure 3 and Figure 4. Here, it can be seen that the optimized data fit well with the available experimental data (plotted using triangular data points). 


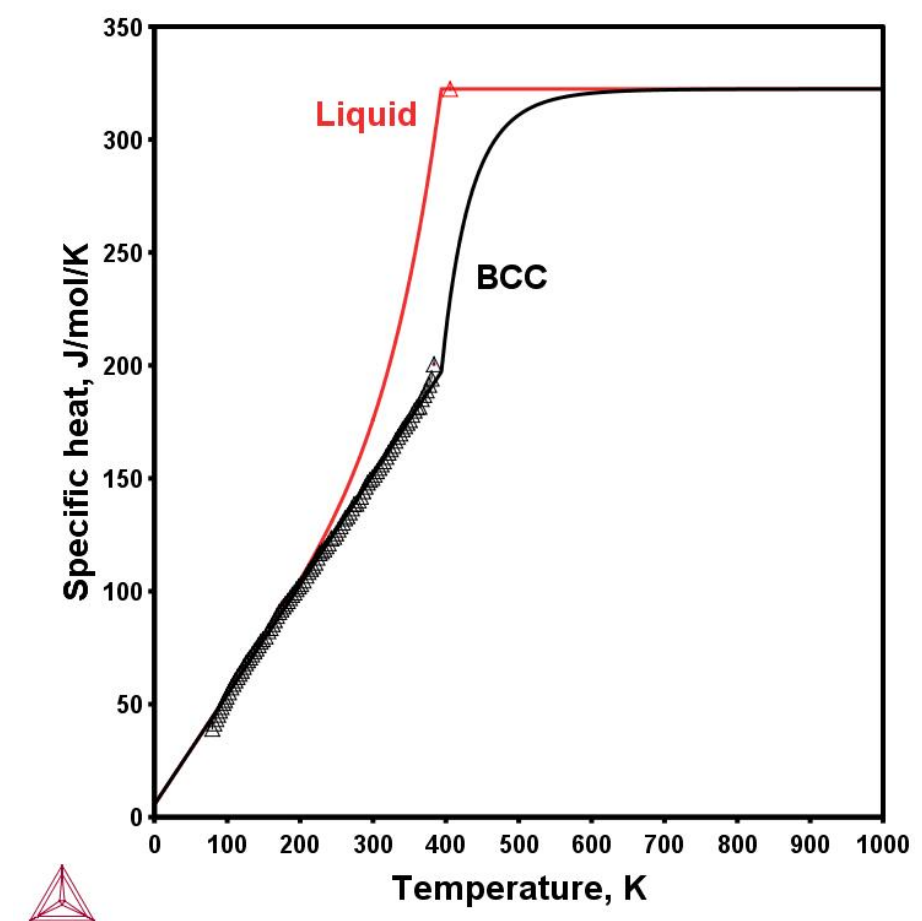

Figure 1. The specific heat of solid (BCC) and liquid erythritol in full temperature range of stable and metastable states. (Here, the solid lines and the triangle points respectively represent the calculated and the experimental data)

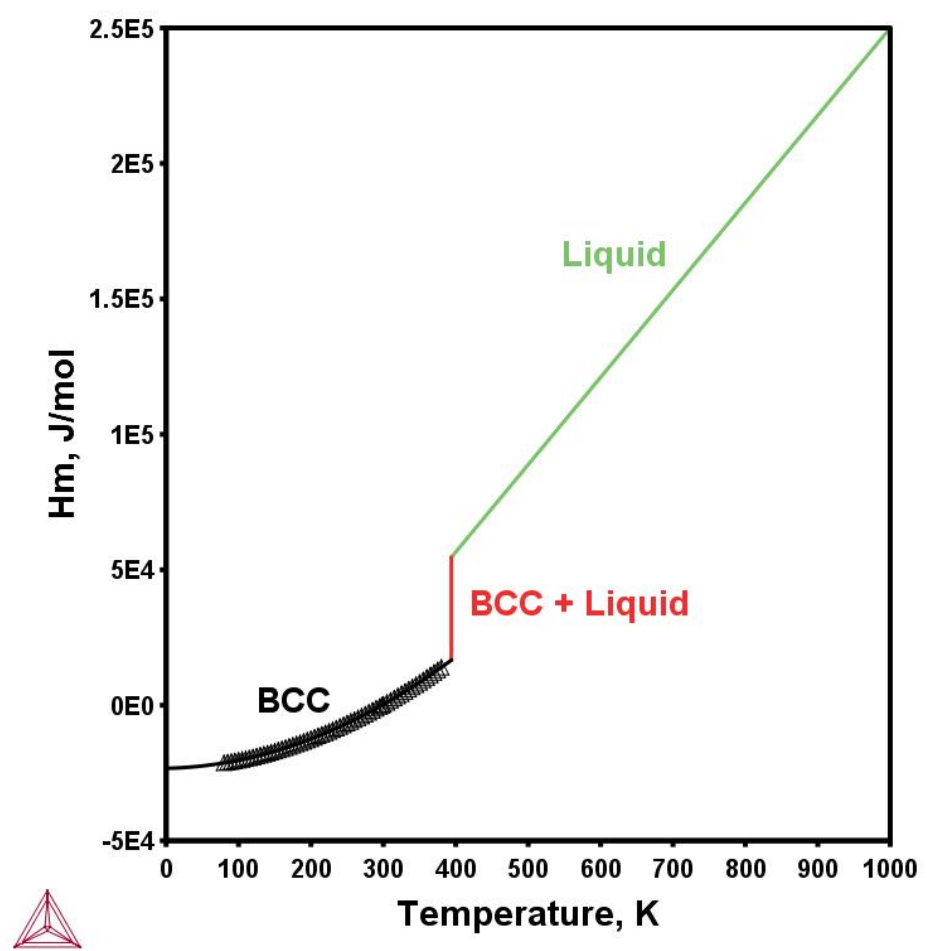

Figure 2. The molar enthalpy $\left(H_{m}\right)$ variations of erythritol (denoted with BCC in the solid state) with reference to room temperature. (Here, the solid lines and the triangle points respectively represent the calculated and the experimental data) 


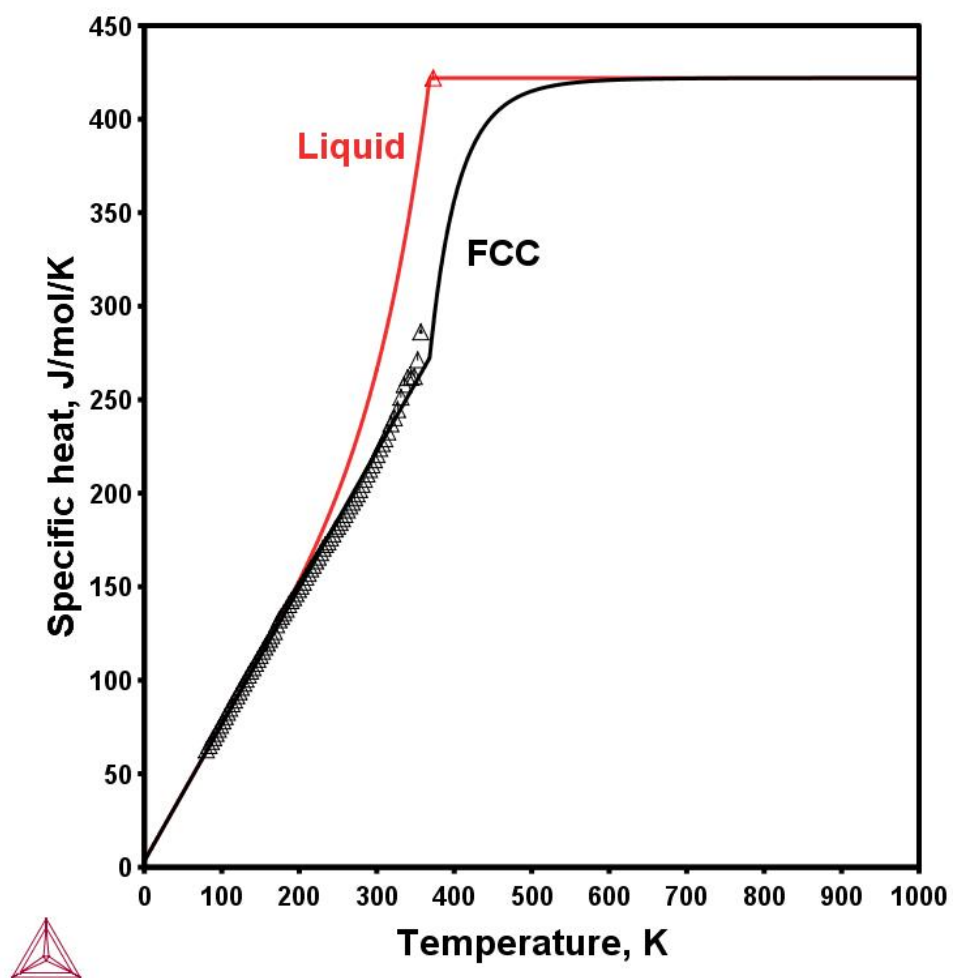

Figure 3. The specific heat of solid (FCC) and liquid xylitol in the full temperature range of stable and metastable states. (Here, the solid lines and the triangle points respectively represent the calculated and the experimental data)

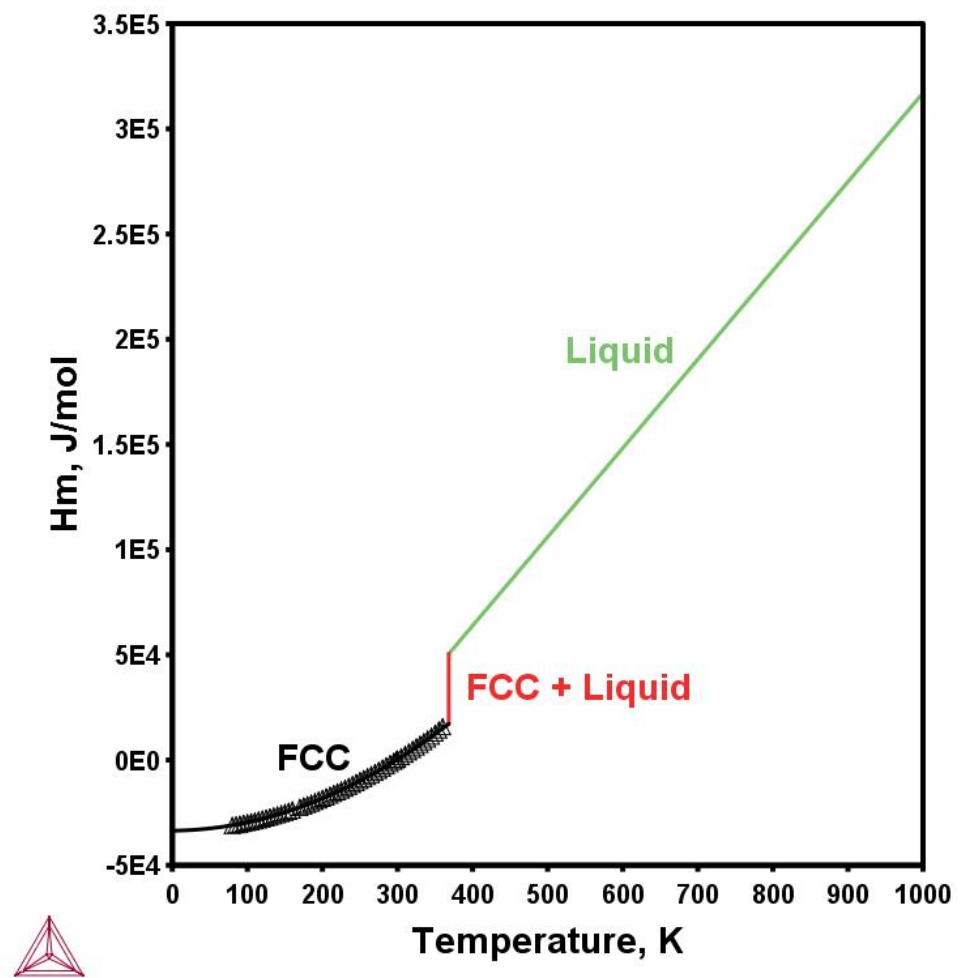

Figure 4. The molar enthalpy $\left(H_{m}\right)$ variations of xylitol (denoted with FCC in the solid state) with reference to room temperature. (Here, the solid lines and the triangle points respectively represent the calculated and the experimental data) 
The calculated binary phase diagram of the erythritol-xylitol system is shown in Figure 5 (in solid lines), plotted together with the employed experimental data from Gunasekara et al. [25] (in data points). Here, for comparison, the calculated liquidus and solidus of the system from literature [19], [20] are also plotted using dotted-lines.

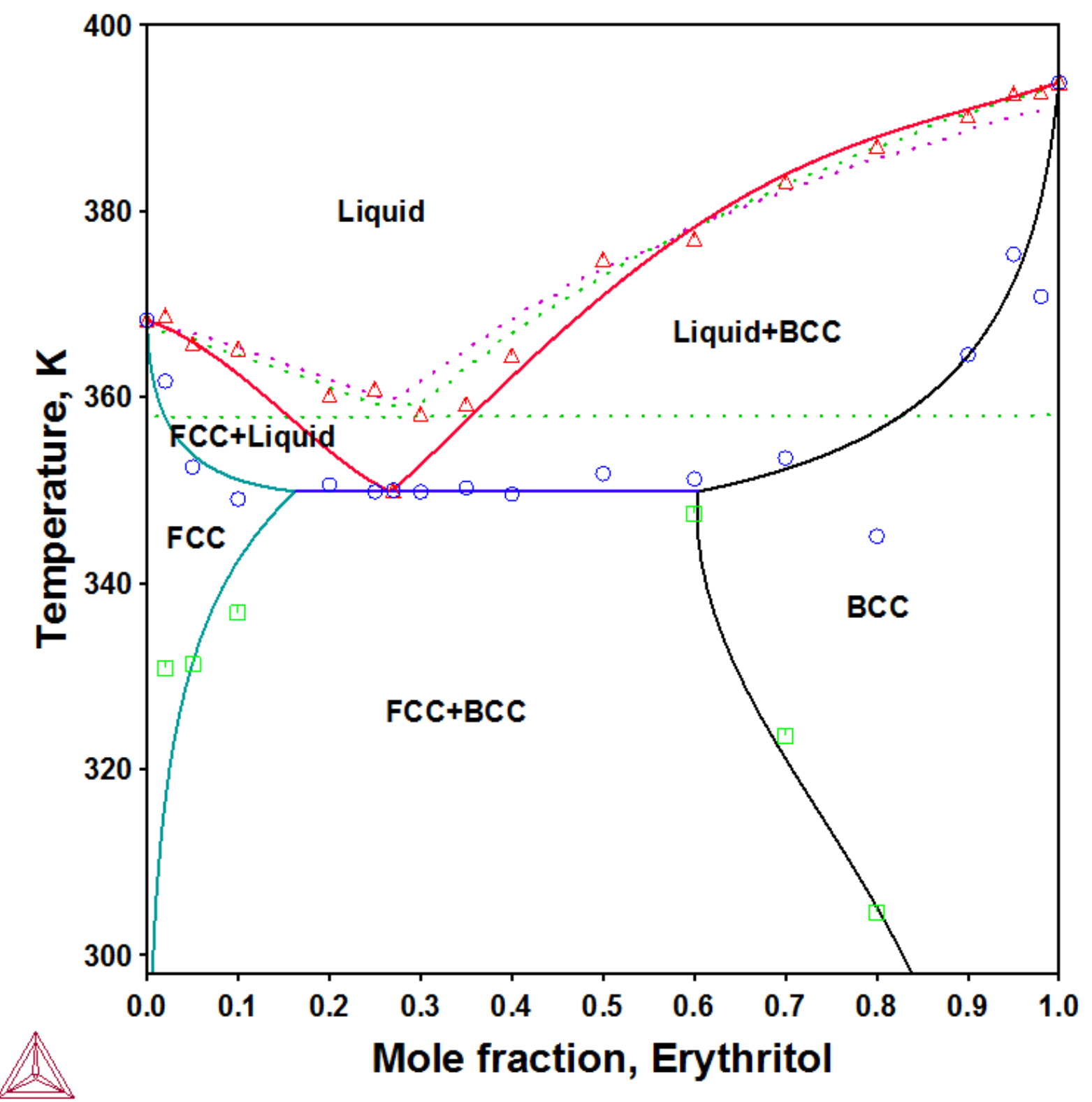

Figure 5. The thermodynamically optimized phase diagram of the erythritol-xylitol system (the calculated phase boundaries in solid lines, and experimental data in triangular, circular or square points. BCC: the crystal structure of the stable solid phase of erythritol and thus its solid solution $S_{E t}, F C C$ : the crystal structure of the stable solid phase of xylitol, or, its solid solution $\left.S_{x y}\right)$. For comparison, the calculated results in literature are also plotted in dotted-lines: in green, the liquidus and solidus from the modified UNIFAC model by Diarce et al. [19]; and in magenta, the liquidus from the ideal solutions approach by Del Barrio et al. [20].

As seen in Figure 5, the calculated data in this work agree rather well for the most of the liquidus and solidus experimental points. This thermodynamic optimization better-verifies the solidus, liquidus, solvus 
and the eutectic point in the system. The thermodynamic assessment here is a valuable contribution especially with the verification of the solidus around the compositions $80-98$ mol\% erythritol and the liquidus around the eutectic point, where the experimental data (from Gunasekara et al. [25]) had larger variations. In addition, this thermodynamic evaluation presents the thermodynamically correct solvus propagation in the phase diagram where the experimental points displayed deviations from a possible trend. Most importantly, the erythritol-xylitol equilibrium phase diagram here calculated based on the optimized thermodynamic parameters verifies the experimental conditions during the study by Gunasekara et al. [25] to have reached stability.

The optimized phase diagram in this work in Figure 5 (in solid lines) can be compared with the nonisomorphous simple eutectic phase diagrams proposed by Diarce et al. [19] using the modified UNIFAC model, and by Del Barrio et al. [20] using ideal solution approach (c.f. section 1.1), plotted using green and magenta dotted lines respectively. Clearly, the earlier phase diagrams are different to the partially isomorphous eutectic phase diagram here. Besides, in their calculated results, Del Barrio et al. [20] have only presented a liquidus, but no solidus for the system. The calculated eutectic temperature and composition in this work are compared to the previous literature data, in Table 2. As Table 2 shows, the calculated eutectic temperature and composition in these non-isomorphous simple eutectic phase diagrams have reasonable dissimilarities between each study ([19], [20]), as well as between their respective experimental data.

Table 2. The erythritol-xylitol eutectic transformation temperature and compositions summary (experimental: onset temperature unless specified)

\begin{tabular}{|c|c|c|c|c|c|}
\hline \multirow{2}{*}{$\begin{array}{l}\text { Eutectic } \\
\text { Transformation }\end{array}$} & \multicolumn{2}{|c|}{ Temperature } & \multirow{2}{*}{$\begin{array}{l}\text { Composition (Mol\% } \\
\text { erythritol) }\end{array}$} & \multirow[t]{2}{*}{ Comment } & \multirow[t]{2}{*}{ Source } \\
\hline & $\mathbf{K}$ & ${ }^{\circ} \mathrm{C}$ & & & \\
\hline \multirow{6}{*}{$\begin{array}{l}\text { Liquid } \rightarrow \\
\text { FCC + BCC } \\
\text { (pure solids) }\end{array}$} & $355.40 /$ & $82.2 /$ & 25 & Experimental, DSC & \multirow[t]{3}{*}{ [19] } \\
\hline & $357.05^{a}$ & $83.9^{a}$ & & & \\
\hline & 358.05 & 84.9 & $\sim 28$ & Theoretical, Modified UNIFAC & \\
\hline & 355.35 & 82.2 & $\sim 28$ & Experimental, IRT & \multirow[t]{3}{*}[20]{} \\
\hline & 355.20 & 82.0 & 36 & Experimental, DSC & \\
\hline & 359.45 & 86.3 & 27.4 & Theoretical, Ideal solution approach & \\
\hline \multirow{2}{*}{$\begin{array}{l}\text { Liquid } \rightarrow \\
\text { FCC + BCC (solid } \\
\text { solutions) }\end{array}$} & 350.20 & 77.0 & $25-30\left(\sim 27^{b}\right)$ & Experimental, T-History & {$[25]$} \\
\hline & $349.90^{c}$ & $76.7^{c}$ & $26.8^{\mathrm{d}}$ & Theoretical & This work \\
\hline
\end{tabular}

The calculated eutectic temperature and composition in this work agree well with the experimental data of Gunasekara et al. [25], used in the optimization. As the non-isomorphous simple eutectic phase diagrams proposed by Diarce et al. [19] or Del Barrio et al. [20] are not comparable with the partially isomorphous eutectic phase diagram here (Figure 5), this eutectic point is also not directly comparable with the earlier studies ( [19], [20]). Nevertheless, the calculated eutectic composition in the present work has reasonable numerical agreements with those found by Del Barrio et al. [20] theoretically via the ideal solution approach, and by Diarce et al. [19] through the DSC experiments. However, the eutectic temperature here is very different to those found by both Diarce et al. [19] and Del Barrio et al. [20]. These 
deviations maybe due to the differences in their employed experimental conditions, and the modeling approaches approximating to dilute or ideal solutions [19], [20] in contrast to accounting the deviations from the idealities herein.

\section{Conclusions}

The erythritol-xylitol binary phase diagram is successfully optimized, using a substitutional solutions model in the CALPHAD method, by employing Thermo-Calc PARROT module. The calculated phase diagram is in good agreement with the experimental liquidus, solidus and the solvus on the system. This evaluation thermodynamically verifies the system's phase boundaries as a partially isomorphous system containing a eutectic. In addition, the calculated results enable the confirmation of the solidus, liquidus, and solvus points that displayed deviations from a common trend during experiments. The calculated eutectic point lies at a temperature of $76.7{ }^{\circ} \mathrm{C}$ and a composition of $26.8 \mathrm{~mol} \%$ erythritol, as compared to the experimental data of $77^{\circ} \mathrm{C}$ and $\sim 27 \mathrm{~mol} \%$ erythritol respectively. Thus, the thermodynamic study verifies the system's thermodynamically optimum eutectic temperature and composition. As a whole, this thermodynamic assessment also confirms that the phase diagram of the system corresponds to the stable equilibrium.

The thermodynamic optimization of the binary phase diagram of the erythritol-xylitol system exemplifies the utility of the CALPHAD method coupling the phase diagram information with thermo-chemical properties such as heat capacities and enthalpy changes at various temperatures. CALPHAD, with flexibility to evaluate any material and phase equilibrium type, is advantageous over the specific theoretical methods employed so far to study the erythritol-xylitol system in literature which were restricted to nonisomorphous simple eutectics. An added advantage with the fundamental Gibbs free energy minimization approaches like CALPHAD method is the ability to predict the multicomponent phase diagrams, provided their sub-systems are already thermodynamically optimized. Therefore, to study and effectively predict multicomponent phase diagrams in the focus of designing PCMs from blends, the fundamental Gibbs free energy minimization approaches like CALPHAD method are instrumental.

\section{Acknowledgements}

The authors express their gratitude to the Swedish Energy Agency for funding the particular research project: 34948-1, and to Thermo-Calc [27] for the free access of the academic edition used in the study.

\section{References}

[1] J. Yagi and T. Akiyama, "Storage of thermal energy for effective use of waste heat from industries," Journal of Materials Processing Technology, vol. 48, pp. 793-804, 1995.

[2] A. Hauer, S. Gschwander, Y. Kato, V. Martin, P. Schossig and F. Setterwall, "Transportation of Energy by Utilization of Thermal Energy Storage Technology," ECES- IEA Annex 18, 2010.

[3] J. N. Chiu, J. Castro Flores, V. Martin and B. Lacarrière, "Industrial surplus heat transportation for use in district heating," Energy, vol. 110, pp. 139-147, 2016.

[4] E. Oró, L. Miró, M. M. Farid, V. Martin and L. F. Cabeza, "Energy management and CO2 mitigation using phase change materials (PCM) for thermal energy storage (TES) in cold storage and transport," International Journal of Refrigeration, vol. 42, pp. 26-35, 2014. 
[5] F. Kuznik, J. P. A. Lopez, D. Baillis and K. Johannes, "Design of a PCM to air heat exchanger using dimensionless analysis: Application to electricity peak shaving in buildings," Energy and Buildings, vol. 106, p. 65-73, 2015.

[6] N. Chaiyat, "Energy and economic analysis of a building air-conditioner with a phase change material (PCM)," Energy Conversion and Management, vol. 94, p. 150-158, 2015.

[7] R. Barzin, J. J. Chen, B. R. Young and M. M. Farid, "Peak load shifting with energy storage and price-based control system," Energy, vol. 92, pp. 505-514, 2015.

[8] S. N. Gunasekara, V. Martin and J. N. Chiu, "Phase Equilibrium in the Design of Phase Change Materials for Thermal Energy Storage: State-of-the-Art," Renewable and Sustainable Energy Reviews, vol. 73, pp. 558-581, 2017.

[9] Y.-C. M. Li and Y.-H. A. Chen, "Assessing the thermal performance of three cold energy storage materials with low eutectic temperature for food cold chain," Energy, vol. 115, no. 1, p. 238-256, 2016.

[10] H. Singh, A. Talekar, W.-M. Chien, R. Shi, D. Chandra, A. Mishra, M. Tirumala and D. J. Nelson, "Continuous solid-state phase transitions in energy storage materials with orientational disorder - Computational and experimental approach," Energy, vol. 91, pp. 334-349, 2015.

[11] S. N. Gunasekara, J. N. Chiu and V. Martin, "Polyols as phase change materials for surplus thermal energy storage," Applied Energy, vol. 162, pp. 1439-1452, 2016.

[12] V. Brancato, A. Frazzica, A. Sapienza and A. Freni, "Identification and characterization of promising phase change materials for solar cooling applications," Solar Energy Materials \& Solar Cells, vol. 160, p. 225-232, 2017.

[13] T. Nomura, M. Tsubota, T. Oya, N. Okinaka and T. Akiyama, "Heat release performance of direct-contact heat exchanger with erythritol as phase change material," Applied Thermal Engineering, vol. 61, pp. 28-35, 2013.

[14] L. Zhichao, Q. Zhang and G. Wu, "Preparation and enhanced heat capacity of nano-titania doped erythritol as phase change material," International Journal of Heat and Mass Transfer, vol. 80, p. 653-659, 2015.

[15] T. Oya, T. Nomura, M. Tsubota, N. Okinaka and T. Akiyama, "Thermal conductivity enhancement of erythritol as PCM by using graphite and nickel particles," Applied Thermal Engineering, vol. 61, pp. 825-828, 2013.

[16] A. Solé, H. Neumann, S. Niedermaier, I. Martorell, P. Schossig and L. F. Cabeza, "Stability of sugar alcohols as PCM for thermal energy storage," Solar Energy Materials \& Solar Cells, vol. 126, p. 125-134, 2014.

[17] C. Rathgeber, L. Miró, L. F. Cabeza and S. Hiebler, "Measurement of enthalpy curves of phase change materials via DSC and T-History: When are both methods needed to estimate the behaviour of the bulk material in applications?," Thermochimica Acta, vol. 596, pp. 79-88, 2014.

[18] SAMSSA, "Sugar Alcohol based Material for Seasonal Storage Applications," European Community's 7th Framework Programme, 2013. [Online]. Available: http://samssa.eu/. [Accessed 09 December 2013].

[19] G. Diarce, I. Gandarias, Á. Campos-Celador, A. García-Romero and U. J. Griesser, "Eutectic mixtures of sugar alcohols for thermal energy storage in the 50-90 C temperature range," Solar Energy Materials \& Solar Cells, vol. 134, p. 215-226, 2015.

[20] E. P. Del Barrio, R. Cadoret, J. Daranlot and F. Achchaq, "New sugar alcohols mixtures for long-term thermal energy storage applications at temperatures between $70{ }^{\circ} \mathrm{C}$ and $100{ }^{\circ} \mathrm{C}$," Solar Energy Materials \& Solar Cells, vol. 155, p. 454-468, 2016.

[21] S. N. Gunasekara, J. N. Chiu and V. Martin, "Binary Phase Equilibrium Study of the Polyols Blend Erythritol-Xylitol with the T-History Method for Phase Change Materials Design," in 13th International Conference on Energy Storage-Greenstock 2015, Beijing, 2015.

[22] A. Paul, L. Shi and C. W. Bielawski, "A eutectic mixture of galactitol and mannitol as a phase change material for latent heat storage," Energy Conversion and Management, vol. 103, p. 139-146, 2015.

[23] T. Nomura, C. Zhu, A. Sagara, N. Okinaka and T. Akiyama, "Estimation of thermal endurance of multicomponent sugar alcohols as phase change materials," Applied Thermal Engineering, vol. 75, pp. 481-486, 2015.

[24] H. Hidaka, M. Yamazaki, M. Yabe, H. Kakiuchi, E. P. Ona, Y. Kojima and H. Matsuda, "New PCMs prepared from erythritolpolyalcohols mixtures for latent heat storage between 80 and $100^{\circ} \mathrm{C}$," Journal of Chemical Engineering Japan, vol. 37, pp. 1155-1162, 2004.

[25] S. N. Gunasekara, J. N. Chiu, V. Martin and P. Hedström, "Phase Change Material Design- the Experimental Phase Diagram Study of the Binary Polyols System Erythritol-Xylitol," Solar Energy Materials and Solar Cells, Vols. Submitted Manuscript (SOLMAT-D-17-00481) under revision, pp. Submitted Manuscript (SOLMAT-D-17-00481) under revision, 2017.

[26] N. Saunders and A. P. Miodownik, "CALPHAD- Calculation of Phase Diagrams, A Comprehensive Guide," in Pergamon Materials Series, vol. 1, R. W. Cahn, Ed., Oxford, PERGAMON (Elsevier Science Ltd), 1998, pp. 1-497.

[27] Thermo-Calc Software, "Thermo-Calc Software- Science," Thermo-Calc Software, 2017. [Online]. Available: http://www.thermocalc.com/. [Accessed 1501 2017]. 
[28] F. Michaud, D. Mondieig, V. Soubzmaigne, P. Negrier, Y. Haget and E. Tauler, "A System with a Less Than 2 Degree Melting Window in the Range Within -31 C and -45 C: Chlorobenzene-Bromobenzene," Materials Research Bulletin, vol. 31, no. 8, pp. 943-950, 1996.

[29] R. Stolk, F. Rajabalee, M. Jacobs, P. Espeau, D. Mondieig, H. Oonk and Y. Haget, "The RI-Liquid Equilibrium System in the Ternary System n-Pentadecane+n-Hexadecane+n-Heptadecane. Calculation of Liquidus Surface and Thermal Windows Comparison with Experimental Data.," Calphad, vol. 21, no. 3, pp. 401-410, 1997.

[30] V. Metivaud, F. Rajabalee, H. A. Oonk, D. Mondieig and Y. Haget, "Complete determination of the solid (RI)-liquid equilibria of four consecutive n-alkane ternary systems in the range $\mathrm{C} 14 \mathrm{H} 30-\mathrm{C} 21 \mathrm{H} 44$ using only binary data," Canadian Journal of Chemistry, vol. 77, pp. 332-339, 1999.

[31] L. Ventolà, T. Calvet, M. Á. Cuevas-Diarte, V. Métivaud, D. Mondieig and H. Oonk, "From concept to application. A new phase change material for thermal protection at $-11^{\circ} \mathrm{C}$," Mat Res Innovat, vol. 6, p. 284-290, 2002.

[32] L. Ventola, T. Calvet, M. A. Cuevas-Diarte, M. Ramírez, H. A. J. Oonk, D. Mondieig and P. Negrier, "Melting behaviour in the n-alkanol family. Enthalpy-entropy compensation," Phys. Chem. Chem. Phys., vol. 6, pp. 1786-1791, 2004.

[33] D. Mondieig, F. Rajabalee, V. Metivaud, H. . A. J. Oonk and M. A. Cuevas-Diarte, "n-Alkane Binary Molecular Alloys," Chem. Mater., vol. 16, pp. 786-798, 2004.

[34] R. Chellappa and D. Chandra, "Phase diagram calculations of organic "plastic crystal" binaries: $(\mathrm{NH} 2)(\mathrm{CH} 3) \mathrm{C}(\mathrm{CH} 2 \mathrm{OH}) 2-$ $(\mathrm{CH} 3) 2 \mathrm{C}(\mathrm{CH} 2 \mathrm{OH}) 2$ system," Computer Coupling of Phase Diagrams and Thermochemistry, vol. 27, p. 133-140, 2003.

[35] R. Chellappa, R. Russell and D. Chandra, "Thermodynamic modeling of the $\mathrm{C}(\mathrm{CH} 2 \mathrm{OH}) 4-(\mathrm{NH} 2)(\mathrm{CH} 3) \mathrm{C}(\mathrm{CH} 2 \mathrm{OH}) 2$ binary system," Computer Coupling of Phase Diagrams and Thermochemistry, vol. 28, pp. 3-8, 2004.

[36] D. Chandra, R. Chellappa and W.-M. Chien, "Thermodynamic assessment of binary solid-state thermal storage materials," Journal of Physics and Chemistry of Solids, vol. 66, p. 235-240, 2005.

[37] A. Mishra, A. Talekar, D. Chandra and W.-M. Chien, "Ternary phase diagram calculations of pentaerythritol-pentaglycerineneopentylglycol system," Thermochimica Acta, vol. 535, p. 17- 26, 2012.

[38] A. Mishra, A. Talekar, R. Shi and D. Chandra, "Thermodynamic assessment of orientationally disordered organic molecular crystals:Ternary system pentaerythritol-neopentylglycol-2-amino-2methyl-1,3,propanediol (PE-NPG-AMPL)," CALPHAD: Computer Coupling of Phase Diagrams and Thermochemistry, vol. 46, p. 108-117, 2014.

[39] P. Mekala, V. Kamisetty, W.-M. Chien, R. Shi, D. Chandra, J. Sangwai, A. Talekar and A. Mishra, "Thermodynamic modeling of binary phase diagram of 2-amino-2-methyl-1,3-propanediol and TRIS(hydroxymethyl)aminomethane system with experimental verification," CALPHAD: Computer Coupling of Phase Diagrams and Thermochemistry, vol. 50, pp. 126-133, 2015.

[40] D. Boa, D. Hellali, D. Licbarski, M. Tizzotti, H. Zamali, C. Favotto, P. Benigni and J. Rogez, "Experimental investigation and calculation of the binary (AgNO3 + KNO3) phase diagram," J. Chem. Thermodynamics, vol. 81, p. 44-51, 2015.

[41] A. Abdessattar, D. Hellali, D. Boa and H. Zamali, "Experimental investigation and calculation of the phase diagram of the binary system (NaNO3-TINO3)," Journal of Alloys and Compounds, vol. 651, pp. 773-778, 2015.

[42] D. Sergeev, E. Yazhenskikh, D. Kobertz, K. Hack and M. Müller, "Phase equilibria in the reciprocal $\mathrm{NaCl}-\mathrm{KCl}-\mathrm{NaNO} 3-\mathrm{KNO} 3$ system," CALPHAD: Computer Coupling of Phase Diagrams and Thermochemistry, vol. 51, p. 111-124, 2015.

[43] R. Shi, I. Gantan, D. Chandra, W.-M. Chien, A. Talekar, A. Mishra, J. Wang, M. Tirumala and D. J. Nelson, "Thermodynamic assessment of binary systems Tris(hydroxymethyl) aminomethane-Pentaglycerine (TRIS-PG) and 2-amino-2-methyl-1,3propanediol-Pentaglycerine (AMPL-PG) phase diagrams," CALPHAD: Computer Coupling of Phase Diagrams and Thermochemistry, vol. 52, pp. 264-273, 2016.

[44] Z. Li, H. Mao, P. A. Korzhavyi and M. Selleby, "Thermodynamic re-assessment of the Co-Cr system supported by firstprinciples calculations," CALPHAD: Computer Coupling of Phase Diagrams and Thermochemistry, vol. 52, p. 1-7, 2016.

[45] A. Bekoe and H. M. Powell, "Crystal structure of i-erythritol and its relationship to soem derived $\mathrm{d}$ and I and racemic substances," Proceedings of The Royal Society Publishing A, pp. 301-315, 25 October 1958.

[46] H. S. Kim and G. A. Jeffrey, "The Crystal Structure of Xylitol," Acta Crystallographica, vol. B25, p. 2607, 1969.

[47] W. D. Callister, Jr., Material Science and Engineering, An Introduction, 7 ed., New York: John Wiley \& Sons, Inc., 2007, pp. 252-303.

[48] B. Tong, Z. C. Tan, J. N. Zhang and S. X. Wang, "Thermodynamic evaluation of several natural polyols- Part III. Heat capacities and thermodynamic properties of Erythritol," Journal of Thermal Analysis and Calorimetry, vol. 95, p. 469-475, 2009.

[49] B. Tong, Z.-C. Tan, Q. Shi, Y.-S. Li, D.-T. Yue and S.-X. Wang, "Thermodynamic investigation of several natural polyols (I): Heat capacities and thermodynamic properties of xylitol," Thermochimica Acta, vol. 457, p. 20-26, 2007. 


\section{Supplementary data}

Table 3. The experimental phase diagram data of the phase diagram used in the thermodynamic assessment, from Gunasekara et al. [25]. (Here, BCC and FCC respectively are the crystal structures of the pure solids of erythritol and xylitol, or, their solid solutions $S_{E t}$ or $S_{X y} . L$ is the liquid, and $t$ is the temperature in ${ }^{\circ} \mathrm{C}$, with the subscripts $s S$, $S$ and Liq representing respectively the solvus, the solidus and the liquidus. And, na means not available)

\begin{tabular}{|c|c|c|c|c|c|c|c|c|}
\hline \multirow{3}{*}{$\begin{array}{l}\text { mole } \\
\text { fraction, } \\
\mathrm{X}_{\mathrm{Er}}{ }^{b}\end{array}$} & & & \multicolumn{6}{|c|}{ Temperatures $^{c}$ and the phases present } \\
\hline & \multicolumn{2}{|c|}{ tss, $\left({ }^{\circ} \mathrm{C}\right)$} & \multirow[t]{2}{*}{ Phases } & \multicolumn{2}{|c|}{$\mathrm{tS},\left({ }^{\circ} \mathrm{C}\right)$} & \multirow[t]{2}{*}{ Phases } & \multirow{2}{*}{$\begin{array}{l}\text { tLiq, offset } \\
\left({ }^{\circ} \mathrm{C}\right)\end{array}$} & \multirow[t]{2}{*}{ Phases } \\
\hline & onset & offset & & onset & offset & & & \\
\hline 0 & na & na & na & na & na & na & 95.2 & FCC \\
\hline 0.02 & 55.2 & 57.7 & $\mathrm{FCC}+\mathrm{BCC}$ & 88.6 & 88.6 & $\mathrm{FCC}+\mathrm{L}$ & 95.6 & $\mathrm{FCC}+\mathrm{L}$ \\
\hline 0.05 & 49.9 & 58.1 & $\mathrm{FCC}+\mathrm{BCC}$ & 79.3 & 82.9 & $\mathrm{FCC}+\mathrm{L}$ & 92.6 & $\mathrm{FCC}+\mathrm{L}$ \\
\hline 0.1 & 52.0 & 63.7 & $\mathrm{FCC}+\mathrm{BCC}$ & 75.9 & 83.1 & $\mathrm{FCC}+\mathrm{L}$ & 92.1 & $\mathrm{FCC}+\mathrm{L}$ \\
\hline 0.2 & na & na & na & 77.4 & 83.1 & $\mathrm{FCC}+\mathrm{BCC}+\mathrm{L}$ & 87.1 & $\mathrm{FCC}+\mathrm{L}$ \\
\hline 0.25 & na & na & na & 76.7 & 86.7 & $\mathrm{FCC}+\mathrm{BCC}+\mathrm{L}$ & 87.8 & $\mathrm{FCC}+\mathrm{L}$ \\
\hline 0.3 & na & na & na & 76.7 & 84.1 & $\mathrm{FCC}+\mathrm{BCC}+\mathrm{L}$ & 85.1 & $B C C+L$ \\
\hline 0.35 & na & na & na & 77.1 & 83.5 & $\mathrm{FCC}+\mathrm{BCC}+\mathrm{L}$ & 86.2 & $B C C+L$ \\
\hline 0.4 & na & na & na & 76.5 & 84.0 & $\mathrm{FCC}+\mathrm{BCC}+\mathrm{L}$ & 91.4 & $B C C+L$ \\
\hline 0.5 & na & na & na & 78.6 & 85.5 & $\mathrm{FCC}+\mathrm{BCC}+\mathrm{L}$ & 101.7 & $B C C+L$ \\
\hline 0.6 & 59.9 & 74.3 & $\mathrm{FCC}+\mathrm{BCC}$ & 78.1 & 83.6 & $\mathrm{FCC}+\mathrm{BCC}+\mathrm{L}$ & 103.9 & $B C C+L$ \\
\hline 0.7 & 48.6 & 50.4 & $\mathrm{BCC}+\mathrm{FCC}$ & 80.3 & 82.8 & $B C C+L$ & 110.1 & $B C C+L$ \\
\hline 0.8 & 26.0 & 31.4 & $\mathrm{BCC}+\mathrm{FCC}$ & 71.9 & 77.3 & $B C C+L$ & 113.9 & $B C C+L$ \\
\hline 0.9 & na & na & na & 91.4 & 93.6 & $B C C+L$ & 117.1 & $B C C+L$ \\
\hline 0.95 & na & na & na & 102.2 & 102.8 & $B C C+L$ & 119.6 & $B C C+L$ \\
\hline 0.98 & na & na & na & 97.7 & 98.0 & $B C C+L$ & 119.7 & $B C C+L$ \\
\hline 1 & na & na & na & na & na & na & 120.7 & $\mathrm{BCC}$ \\
\hline
\end{tabular}

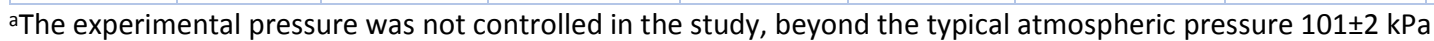
${ }^{b}$ The expanded uncertainty of the molar composition, with a 0.95 level of confidence is $1.3 \%$

'The expanded uncertainty of the temperature, with a 0.95 level of confidence is $0.4{ }^{\circ} \mathrm{C}$ 